\title{
Fibrosis: The sixth element
}

\author{
Alcibey Alvarado* \\ Internal Medicine and Neumology Clínica de Diagnóstico Médico. San José, Costa Rica
}

\begin{abstract}
Disease-related injury in any organ triggers a complex cascade of cellular and molecular responses that culminates in tissue fibrosis. This monograph describes the molecular, cellular and immunological characteristics that occur in an inflammatory process, until it ends in fibrosis; and particularly when the phenomenon persists, leading to an activation that does not remit from the effector cells, chronifying the process, healing the tissue or the organ, generating specific pathologies and dysfunction. The article is illustrated with some examples of fibrotic diseases, discussing their pathogenesis, clinical picture and treatment, particularly in light of new immunopathogenic findings. The preponderant role of early therapeutic interventions to block the evolution towards tissue scar is highlighted. In the end, recommendations are made about the avenues of investigation that must be followed in this final stage of the inflammatory process.
\end{abstract}

\section{Introduction}

Inflammation is a term credited to Celsus. It was used as a metaphor because the dermal response to injury was reminiscent of a fire, characterized by redness (rubor), heat (calor), swelling (tumor), and pain (dolor), and some of these Latin terms are used today in medical schools. Virchow described a fifth change, loss of function (functio laesa). A sixth change, repair, could also be added, because a new growth occurs after tissue injury, just like after the fire occurs in the forests, prairies and even cities in an attempt to preserve the function and life [1]. When injury and inflammatory responses are abrogated, resorption of extracellular matrix proteins occurs, promoting organ repair. When chronic injury persists, the unremitting activation of effector cells results in the continuous deposition of extracellular matrix, progressive scarring and organ damage [2].

Rockey and others have proposed 4 phases of the fibrogenic response. The first phase is the beginning of the response to the injury to the organ. The second phase is the activation of effector cells and the third is the elaboration of extracellular matrix proteins (ECM). The fourth phase is the deposit of these proteins in a dynamic model, in which, not only the deposit is increased, but the reabsorption of ECM is also reduced, promoting the progression to fibrosis and finally the failure of the organ [2]. The "wounding response" is activated by complex activities within different cells that generate specific molecules with programmed action pathways. The cellular component includes inflammatory cells (eg, polymorphonuclear cells, macrophages, $\mathrm{T}$ lymphocytes, etc.), epithelial and endothelial cells and fibrogenic effector cells that are the ones that will produce and release ECM proteins. These effector cells include fibroblasts, myofibroblasts, cells derived from bone marrow, fibrocytes, epithelial cells in transition to mesothelial cells (EMT), endothelial cells in transition to mesothelial cells (EndMT), and mesothelial cell in transition to mesenchymal cells (MMT). A number of molecules are critical to transmit and control information between the cells that suffer the initial injury and the effector cells that produce ECM. The deformity of the organ produces dysfunction, but it must be emphasized that this is a dynamic, active and ductile phenomenon, although the fibrogenic plasticity varies from organ to organ.

\section{Pathogenesis}

Both acute and chronic inflammation can develop fibrosis. Inflammation damages the epithelial and endothelial cells leading to the production and release of inflammatory mediators (cytokines, chemokines and others) that recruit a wide range of inflammatory cells (PMNs, eosinophils, basophils, mastocells, T lymphocytes and macrophages). These cells, in turn, release profibrotic mediators which activate effector cells that manage the fibrogenic process [3]. The molecular factors that direct and control the fibrotic process are broad and complex. One of these factors, which is practically present in almost all fibrotic processes, is the transforming growth factor beta (TGF- $\beta$ ). This factor involves the binding of a ligand to a serine-threonine kinase type II receptor that recruits and phosphorylates to type I receptor. This type I receptor then phosphorylates SMADs that modulate the gene expression of the genes that code for the activity of fibrogenic factors. SMAD is an acronym from the fusion of Caenorhabditis elegans Sma genes and the Drosophila Mad Mothers against decapentaplejic proteins to transducer signals. Actually TGF- $\beta$ is a superfamily that involves multiple cascades of signals [4]. TGF- $\beta$ is a potent stimulator of fibrogenic cells for the production of ECM proteins $[5,6]$.

Other profibrotic factors that stimulate ECM production are: platelet-derived growth factor (PDGF), connective tissue growth factor (CTGF), vascular endothelial growth factor (VEGF), IL-1, IL-4, IL -6, IL-10, TNF- $\alpha$. Also vasoactive peptides play an important role in the deposition process of ECM, such as angiotensin II and endothelin I [7]. This latter peptide has a role in fibrosis in practically all organs by acting on the receptor coupled to $G$ protein of endothelin-A or on the cellular receptor of endothelin-B or both [8]. Integrins, which

*Correspondence to: Alcibey Alvarado, Clínica de Diagnóstico Médico, Torre Médica, 3 piso, Paseo Colón, San José, América Central, Costa Rica, Tel: 50622237134; 50622566439; 50687351858; Fax: 50622216754; E-mail: alcialvagonza@yahoo.com.mx

Key words: inflammation, inflammatory mediators, tissue scar, fibrosis

Received: October 01, 2018; Accepted: November 19, 2018; Published: November 23, 2018 
bind extracellular matrix to cells, are also critical in the pathogenesis of fibrosis [9].

These factors will stimulate the effector cells to release ECM. The matrix proteins that form the fibrotic scar are mainly collagen I and III (synthesized from pro-collagen), cellular fibronectin, basement membrane proteins such as laminin, proteoglycans and aggrecan. Myofibroblasts express smooth muscle proteins, including actin (ACTA2), which is contractile. The contraction of these cells contributes to the distortion of the parenchymal architecture, but this remodeling confers a dynamism character to the tissue and may have important therapeutic implications [2]. The fibrogenic process therefore involves an interrelation between biosynthesis, deposition and ECM degradation. The synthesis is counterbalanced by degradation by matrix metalloproteinases (MMPs) (collagenases and gelatinases), whose activity in turn is controlled by tissue inhibitors of metalloproteinases (TIMPs). Collectively MMPs and TIMPs determine the general rate of ECM degradation [10,11]. In addition, the process is governed by the elimination of effector cells by senescence, apoptosis and autophagy.

The role of genetics in the pathogenesis of fibrosis goes "in crescendo". For example, in the kidney, fibrosis is a prominent change of karyomegalic interstitial nephritis, which is caused by mutation in the gene encoding Fanconi anemia-associated nuclease 1 (FANI) [12]. In the liver, PNLAP3 is important in ethanol-mediated fibrosis and associated with fatty liver disease and there are a number of candidate genes that may be important in hepatic fibrosis induced by infection with the hepatitis $C$ virus [13-15]. Primary myelofibrosis (PMF) can be associated with mutations of the JAK2, CALR, MPL genes [16]. HCM (hypertrophic cardiomyopathy) is a relatively common genetic disorder of cardiac sarcomeres, characterized by left ventricular hypertrophy and represents the most common cause of sudden cardiac death among young athletes [17]. Mutations in TERT, TERC, PARN, RTL1, genes involved in the maintenance of telomere length, are associated with an increased risk of idiopathic pulmonary fibrosis (IPF) $[18,19]$. Variations in genes (DSP, AKAP13, CTNNA, and DPP9) that are responsible for cell adhesion, integrity, and mechanotransduction (the generation of electrical signals from mechanical stimuli) also confer a predisposition for IPF $[20,21]$.

A single-nucleotide polymorphism (rs35705950) in the promoter region of MUC5B substantially increases the risk of IPF [22]. MUC5B codes for mucin $5 \mathrm{~B}$, a glycoprotein required for airway clearance and innate immune responses to bacteria [23]. The rs35705950 minor allele leads to overexpression of mucin 5B in small-airway epithelial cells, to universal finding in patients with IPF (regardless of the MUC5B genotype). Although the mechanism linking mucin 5B overexpression and IPF risk remains unknown, some researchers have hypothesized that aberrant mucociliary clearance may lead to alterations in the lung microbiome and innate immune responses that promote IPF [24-26].

The epigenetic regulation of gene expression, which includes but is not limited to DNA methylation, post-translational modifications of chromatin histones, and regulatory microRNAs (miRs), is important in fibrosis. The miRs play a role in expanding genetic regulation. In diabetic nephropathy, TGF- $\beta$ promotes the expression of mi-R192, which results in collagen deposition [27], and miR-19b regulates TGF- $\beta$ signals in hepatic stellate cells [28]. In the heart, miR-21, miR-29, miR30 and miR-133 participate in the remodeling of the myocardial matrix [29]. Fibroblasts from patients with IPF have global changes in DNA methylation, which are not found in normal lung fibroblasts [30].

\section{Clinical examples}

Fibrosis is a pathological change of disease in virtually all organs (Table 1). Here are some examples of fibrosis,

\section{Cardiac fibrosis}

Heart failure (HF) is a malignant and fatal disease. The incidence of heart failure is $1-2 \%$ in developed countries and increases to $10 \%$ in those over 70 years, with only $35 \%$ of survival to 5 years after diagnosis [31]. A key mechanism of $\mathrm{HF}$ is cardiac remodeling, which includes 2 aspects: injury to cardiomyocytes and myocardial fibrosis. There are two types of myocardial fibrosis: fibrosis by replacement and interstitial fibrosis (reactive). Reactive fibrosis occurs in perivascular spaces and corresponds to a fibrogenic response similar to that of other tissues; fibrosis due to replacement occurs at the site of myocyte loss, as occurs in necrosis due to myocardial infarction. Both lead to ECM deposit.

The damaged myocardium releases DAMPs (danger-associated molecular patterns) that are molecules that activate macrophages, mastocells and lymphocytes at the site of injury. For example, one of these molecules (CCL-2 = C-C motif chemokine 2) recruits monocytes inducing their proliferation and mobilization of bone marrow into the inflammatory compartment as precursors of macrophages [32]. Macrophages (M1 and M2) release inflammatory mediators (which attract more cells amplifying inflammation) and profibrotic factors (TGF- $\beta$, PDGF, IL-10, angiotensin II, and endothelin I) that activate fibrogenic effector cells [33]. Inhibiting macrophage infiltration could prevent the development of fibrosis [34]. Mastocells release, in addition to the fibrogenic factors, tryptase and chymase. The latter, via angiotensin II, can activate the TGF- $\beta$ / SMAD axis and promote fibrosis. Blocking TGF- $\beta$ with antibodies could suppress the production of collagen induced by chymase [31]. Infiltration with $\mathrm{T}$ lymphocytes is associated with progression of HF. There are 4 subsets of T lymphocytes: $\mathrm{T}$ helper (Th1 and Th2), T regulatory (Treg) and

Table 1. Fibrogenesis and organ system. Selected organs and associated diseases are highlighted

\begin{tabular}{|c|c|}
\hline Eye & Strabismus \\
\hline \multirow{3}{*}{ Skin } & Scleroderma \\
\hline & Keloid \\
\hline & Nephrogenic systemic fibrosis \\
\hline \multirow{3}{*}{ Pulmonary fibrosis } & Restrictive lung disease \\
\hline & Pulmonary hypertension \\
\hline & Right-side heart failure \\
\hline \multirow{3}{*}{ Cardiac fibrosis } & Diastolic dysfunction \\
\hline & Heart failure \\
\hline & Arrhythmia \\
\hline \multirow{3}{*}{ Renal fibrosis } & Chronic kidney disease \\
\hline & Hypertension, anemia \\
\hline & Electrolytes disturbances \\
\hline \multirow{8}{*}{ Cirrhosis } & Portal hypertension \\
\hline & Ascites \\
\hline & Gastroesophageal varices \\
\hline & Hepatorenal syndrome \\
\hline & Hepatopulmonary syndrome \\
\hline & Portopulmonary syndrome \\
\hline & Hepatic encephalopathy \\
\hline & Hepatocellular cancer \\
\hline \multirow{4}{*}{ Pancreatic fibrosis } & Chronic pain \\
\hline & Diabetes mellitus \\
\hline & Malabsorption \\
\hline & Cancer \\
\hline
\end{tabular}


Th17. Th1 media collagen-cross-linking in left ventricle leading to diastolic dysfunction; Th2 releases IL-13 and IL-14 and Th17 produces IL-17, all of which promote the production of collagen. Treg attenuates myocardial fibrosis and is the main mechanism of protection from injury to cardiomyocytes.

Although proinflammatory cytokines, ROS, TGF- $\beta$, reninaldosterone-angiotensin regulate the process of myocardial fibrosis, recent studies describe some other emerging molecules involved in the fibrogenic process. Such is the case of cardiotrophine-1, nicotinamide adenine dinucleotide phosphate oxidase and several matricellular proteins that are involved in the activation of myofibroblasts and collagen cross-linking. These molecules are under intense investigation as diagnostic and therapeutic objectives $[35,36]$.

TGF- $\beta 1$ (one of the 3 isoforms of TGF- $\beta$ ) activates the conversion of fibroblasts (the most abundant cell in the myocardium) to myofibroblasts and activates the production of collagen, mainly I and III [37]. Cardiomyopathy associated with TGF- $\beta 1$ is associated with valvular thickening, valvular dysfunction, systolic and diastolic dysfunction, and electrophysiological abnormalities and repolarization disorders. The collagen in the septa generates areas of arrhythmogenic fibrosis by inducing a slow discontinuation of the conduction and also an alteration of the reentry circuits due to spatial heterogeneity [38-41]. Fibrotic scar in heart correlates strongly with arrhythmias and sudden cardiac death.

Markers of myocardial fibrosis such as Galactin-3 and ST-2 (a member of the IL-1 receptor family) have produced dissimilar results [42]. miRNAs and pro-Collagen Type I (PICP) and Amino-Terminal Pro-Peptide of Pro-Collagen Type III (P III NP) are not very specific because they are not only associated with myocardial but also hepatic and pulmonary fibrosis.

Nuclear Magnetic Resonance (MR) with Gadolinium is a recent method of research and diagnosis. Last Gadolinium Enhancement (LGE) is defined excessively in the myocardium due to the lengthening of the extracellular space by the deposit of ECM. The patterns of LGE-MR could help identify the causes of heart failure, especially cardiomyopathies [43]. At the prognostic level, the amount of highscale threshold on CMR correlates positively with the possibility of adverse cardiovascular outcomes in patients with end C \& D heart failure (adjusted hazard ratio $1.46 / 10 \%$ increase in LGE: $p=0.003$ ) [44]. There is no "best threshold" that perfectly matches the extent of the fibrosis and the intensity of the LGE signal is not precise enough to differentiate the types of fibrosis (for example, the interstitial vs. the replacement). T1 "mapping" has a prominent advantage to detect diffuse fibrosis because it evaluates the relaxation time of myocardial tissue.

The ECV (extracellular volume fraction) evaluates myocardial fibrosis by measuring T1 mapping analysis pre- and post-contrast. Myocardial ECV is higher in patients with non-ischemic dilated cardiomyopathy than in normal individuals, and may identify early interstitial fibrosis. ECV can be an important method to assess mechanical and physiological abnormalities in patients with HCM, a relatively common genetic disorder of cardiac sarcomeres that presents with hypertrophy of the left ventricle and is the most frequent cause of sudden death among young athletes [45]. Although endomyocardial biopsy could be considered as the "gold standard" for detecting myocardial fibrosis, the ethical and moral regulations and the invasive nature do not allow apply it in a generalized way.

\section{Hepatic fibrosis}

Liver fibrosis is a frequent and potentially fatal complication of many chronic diseases that affect hepatocytes or biliary cells, and represents a high medical and economic burden. Although it is true that molecular knowledge of pathogenesis has advanced considerably at the experimental level, the transfer to the clinical part is limited and pharmacological treatment is generally effective only in experimental models [46]. The different etiological agents damage the hepatocytes, inducing an inflammatory response that involves the local vascular system and the immune system, causing the systemic mobilization of endocrine and neurological mediators. This response involves endothelial cells, stellate cells and resident immune cells (macrophages $=$ Kupffer cells, dendritic cells and mastocells), which contain surface receptors that sense bacterial toxins (PAMPs) and molecules released from the injured tissue (DAMPs) by releasing a variety of different inflammatory and profibrotic mediators within the liver tissue. Numerous molecular pathways participate, as do those found in other organs, but a pathway that seems to be exclusive until this time of liver is the one that uses the toll-like receptor 4 (TLR4) [47]. TLR4 is activated on the surface of the stellate cells by bacterial intestinal lipopolysaccharides derived from the intestine (translocated bacteria), activating fibrogenic effector cells, linking fibrosis and microbiome [48]. Although a variety of effector cells synthesize ECM, hepatic stellate cells appear to be the major source of ECM in the liver. There is sufficient evidence that these cells, similar to pericytes, undergo myofibroblastic transformation in response to injury.

Hepatic fibrosis can be caused by different etiologies including genetic disorders, chronic viral infection, excessive alcohol consumption, autoimmune attack, metabolic disorders, decreased bile flow, venous obstruction and parasitic infection [49]. But also excess lipids and other lipotoxic agents produce endoplasmic reticulum stress, impaired mitochondrial function and oxidative stress in parenchymal and non-parenchymal hepatic cells, and modifications in the microbiotic composition of the gastrointestinal tract or its integrity may be associated with nonalcoholic fatty liver disease and hepatic fibrosis [50]. The progression of liver disease can be triggered by the acidic bile composition. Bile acids are amphipathic molecules with manifold physiological functions. On the one hand, they facilitate the emulsification of dietary fats and assist the intestinal absorption of lipids and fat-soluble vitamins [51]. On the other hand, they act like hormones and are embedded in a complex signal cascades, The most important targets of bile acids are the farnesoid X receptor (FXR) and the $\mathrm{G}$ protein-coupled membrane receptor 5 (TGR5), which activate the expression of genes involved in the metabolism of bile acids, lipids and carbohydrates. Bile acids also have antimicrobial action [52].

The end result of hepatic fibrogenesis is cirrhosis, an ominous parenchymal lesion that underlies a wide range of devastating complications that have adverse effects on survival. Portal hypertension, a devastating result of injury, develops during the fibrogenic response after disruption of the normal interaction between sinusoidal endothelial cells and hepatic stellate cells; the resulting activation and contraction of pericytes-like stellate cells leads to sinusoidal constriction and increased intrahepatic resistance. This increase in resistance in turn activates abnormal signaling by smooth-muscle cells in mesenteric vessels. An increase in angiogenesis and collateral blood flow follows, resulting in an increase in mesenteric blood flow and a worsening of portal hypertension [50]. The major clinical sequelae of portal hypertension, variceal hemorrhage and ascites, emerge relatively late, after the portal pressure rises to a hepatic venous pressure gradient of more than $12 \mathrm{~mm} \mathrm{Hg}$ [53]. 


\section{Renal fibrosis}

Renal fibrosis is characterized by an excessive deposit of ECM in the interstitial compartment, leading to scar formation [54]. The kidneys are susceptible to hypertension and diabetes, the two leading causes of renal fibrosis. As in other organs, renal fibrosis is mediated by cellular elements and molecular elements, but among the factors that stimulate ECM in renal fibrosis, TGF- $\beta 1$ is the main responsible. It is the most potent and ubiquitous profibrotic factor, which acts through intracellular signals such as protein-kinases and transcription factors, and is involved not only in ECM deposition, but also in hypertrophic renal proliferation and renal cell apoptosis. The renin-angiotensinaldosterone system is particularly important in renal fibrosis induced by hypertension [55]. Myofibroblasts are the major source of ECM: a-smooth muscle actin-positive myofibroblasts. A pathogenic pathway of renal fibrosis is the defects of the metabolism of fatty acids in tubular epithelial cells with accumulation of intracellular lipids [56]. Basically what exists is an enzymatic defect in the oxidation of fatty acids (FAO). TGF- $\beta 1$, the most potent profibrotic cytokine, inhibits the expression of carnitine palmitoyltransferase 1 (CPT1), the rate-limiting enzyme in FAO, and that decreases fatty acid metabolism. Accumulated fatty acids damage cells that generate signals for the proliferation of myofibroblasts and renal fibrogenesis [57].

Another pathogenic pathway is the program of transformation of epithelial cells to mesenchymal cells, which generates fibrogenesis (EMT). Therefore, inhibiting the EMT program and blocking or inducing (genetic or pharmacological ablation) a reduction in the population of myofibroblasts could in the future reduce the progression to fibrosis after injury $[58,59]$. Injury to any of the elements of renal cellular architecture (glomeruli, tubules, interstitium and capillaries) triggers the EMC deposit. The location determines the clinical consequence. The immune deposits are located in the glomeruli producing glomerulonephritis, while the injury of the tubulointerstitial environment (NSAIDs, infection, polycystic kidney disease, urinary obstruction) produces tubulo-interstitial fibrosis [60].

Glomerular fibrosis, regardless of the cause, diminishes renal blood flow, which leads to hypoxia and the activation of hypoxiainducible factor 1 , which in turn triggers nephron collapse and fibrotic replacement by means of rarefaction [61]. Regardless of the initiating insult, renal fibrosis leads to loss of function and organ failure. Homeostasis can be maintained with a glomerular filtration rate as low as approximately $10 \%$ of the normal rate. As the mechanisms maintaining homeostasis are progressively disrupted, anemia develops and the regulation of electrolyte balance and $\mathrm{pH}$ is disrupted.

\section{Pulmonary fibrosis}

The family of interstitial lung diseases is characterized by cellular proliferation, interstitial inflammation, fibrosis, or a combination of such findings within the alveolar wall that is not due to infection or cancer [62]. Interstitial fibrosis is the predominant phenotype in most cases. The majority of patients with interstitial fibrosis ultimately receive a diagnosis of chronic hypersensitivity pneumonitis (due to mold or bird exposure), pulmonary sarcoidosis, an underlying autoimmune disease, drugs, environmental exposures (e.g., silica dust or asbestos), or if no cause is identified, an idiopathic interstitial pneumonia. The most common idiopathic interstitial pneumonia is idiopathic pulmonary fibrosis (IPF), a chronic, progressive, fibrotic interstitial lung disease of unknown cause, often with characteristic imaging and histologic appearances that occurs primarily in older adults [63]. The increased rate of hospitalizations and deaths suggests an increased burden of a disease that occurs worldwide. The incidence of IPF is higher in the USA and Europe (3-9 cases per 100,000 personsyear) and the prevalence is 494 cases per 100,000 in adults over 65 years $[64,65]$.

The chronic history of exercise dyspnea is practically universal in this entity, accompanied by chronic cough without purulence and fatigue. With the progression, bilateral Velcro-like crackles, clubbing and acrocyanosis appear. The three typical functional findings are reduced DLCO, hypoxemia at rest or desaturation with exertion, and a normal or low FVC. Conventional radiography shows nonspecific changes or bilateral basal reticular abnormalities. High resolution CT (supine, inspiratory and expiratory decubitus and with thin reconstruction $[<1.25 \mathrm{~mm}])$, in the absence of a specific cause of fibrosis, will identify the UIP pattern (usual interstitial fibrosis), diagnosis of IPF. Lung biopsy will be done only if the combination of clinical, functional and imaging data is not diagnostic, and if the histological result is expected to influence the therapeutic decision. The procedure of choice is thoracoscopy of multiple lobes and avoiding the most fibrotic areas. Progressive pulmonary fibrosis also leads to pulmonary hypertension, right-sided heart failure, and ultimately respiratory failure. It is frequently confused with heart failure or COPD [66].

A conceptual model of pathogenesis is that the recurrent subclinical epithelial injury is superimposed on an accelerated epithelial aging, which leads to an aberrant repair of the injured alveoli and deposition of ECM by myofibroblasts. Apparently senescence of epithelial cells is a central phenotype that favors pulmonary fibrosis [67]. Shortened telomeres, oxidative stress, proteostatic dysregulation, endoplasmic reticulum stress, and mitochondrial dysfunction decrease epithelial alveolar cell proliferation and increase the secretion of profibrotic mediators [68,69]. A study has identified abundance of prevotella, veillonella and escherichia in the bronchioloalveolar lavage of patients with IPF and abundance of streptococcus and staphylococcus have been associated with an increased risk of disease progression [70,71]. A number of non-genetic risk factors for IPF have been identified. Older age, male sex, and cigarette smoking are considered risk factors for IPF [72]. Observational data have implicated gastroesophageal reflux, [73], obstructive sleep apnea [74], air pollution [75], herpesvirus infection [76], and certain occupational exposures in interstitial lung disease.

\section{Other form of fibrosis}

Fibrosis also occurs in the joints, bone marrow, brain, eyes, intestines, peritoneum and retroperitoneum, pancreas, mediastinum and skin, and in these cases is driven by typical cellular and molecular processes. Mediastinal fibrosis is a rare disease mainly associated with histoplasmosis (USA), blastomycosis, aspergillosis, mucormycosis and cryptococcosis. It has also been associated with other granulomatous diseases (tuberculosis and sarcoidosis), autoimmune processes (Behçet's disease, rheumatoid arthritis, systemic lupus erythematosus), neoplasms (lung adenocarcinoma, Hodgkin's lymphoma), and radiotherapy [77]. Clinical features include the involvement of mediastinal structures such as superior vena cava, inferior vena cava, pulmonary arteries and veins, esophagus, and heart. Postulated pathogenic mechanisms include an abnormal autoimmune response to chronic infection and a fibrotic response that invades the mediastinum [78]. Retroperitoneal fibrosis is a rare condition characterized by inflammation and fibrosis in the retroperitoneal space; Most cases are idiopathic, but secondary causes include drugs, infections, autoimmune and inflammatory stimuli, and radiation. The major clinical sequelae of this condition are related to its involvement with structures in the 
retroperitoneum, including arteries (leading to chronic renal failure) and ureters (leading to hydronephrosis). Primary myelofibrosis (PMF) is a myeloproliferative neoplasm characterized by a clonal proliferation derived from stem cells that usually, but not always, is accompanied by mutations (already described in the pathogenesis section), abnormal expression of cytokines, bone marrow fibrosis, splenomegaly, extramedullary hematopoiesis, constitutional symptoms, cachexia, leukemic progression and reduced survival [79].

In certain cancers, fibrosis is linked to TGF- $\beta$-integrin signaling [80]. In scleroderma, the prototypical fibrosing skin disease, skin fibroblasts and myofibroblasts are activated through the TGF- $\beta$-SMAD signaling pathway [81]. Nephrogenic systemic fibrosis, a debilitating condition that is marked by widespread organ fibrosis, occurs in patients with renal insufficiency who have been exposed to gadoliniumbased contrast material. Initial systemic inflammatory-response reactions and the reaction of gadolinium $(\mathrm{Gd} 3+)$ ions with circulating proteins and heavy metals lead to the deposition of insoluble elements in tissue. Since no effective therapies have been identified, prevention is key. A recently recognized IgG4-related disease appears to involve autoimmune-driven inflammation that provokes fibrosis in multiple organs, including the pancreas, retroperitoneum, lung, kidney, liver, and aorta [82].

\section{Therapy}

Fibrosis and resultant organ failure account for at least one third of deaths worldwide [83]. Since fibrosis is common and has adverse effects in all organs, it is an attractive therapeutic target. Elimination of the inciting stimulus is the first and most efficacious approach. Fibrosis of parenchymal tissue usually progresses slowly, which suggests that therapy may be required for extended periods; slowing the progression of fibrosis may be a more realistic therapeutic goal than eliminating it. Fibrosis occurs by means of a dynamic process that involves the synthesis and deposition of extracellular matrix, and its reversion occurs by means of the elimination of effector cells and shifts in the balance of matrix synthesis and degradation. Although it is not clear what pathogenic or clinical factors promote reversibility, the regression of fibrosis has been shown to lead to improved clinical outcomes. The best indication that fibrosis is reversible and that this reversibility has positive effects on clinical outcomes is based on the treatment of liver and pulmonary fibrosis $[84,85]$.

\section{Heart}

During the past several decades, the medical treatment of HF has dramatically progressed. Pharmacologic therapies in clinical use for heart failure that target the primary underlying disease appear to have a secondary effect on fibrosis. Traditional medical interventions to improve the prognosis of HF are beta-blockers, ACE inhibitors, and aldosterone antagonists. These three first-line interventions are called the "Golden Triangle" of HF treatment.

New approaches include decreasing production or increasing collagen degradation. Seralaxin is a recombinant form of human relaxin-2, inhibits cross-linking and collagen synthesis, and has entered into phase III clinical studies for heart failure [86]. Some studies indicate that the diuretic torasemide can inhibit lysyl-oxidase to limit the speed of collagen crosslinks and thus reduce myocardial fibrosis. The anti-TGF- $\beta 1$ antibody can suppress collagen synthesis, but it is not specific for myocardium, since the inhibition of TGF- $\beta 1$ signals is systemic and may generate unexpected results in the attempt to suppress myocardial fibrosis. Studies in animals blocking miRNAs
(anti-miRs) with oligonucleotides appear to reduce interstitial fibrosis, but there are still no clinical studies.

There are drugs that target the degradation of collagen. There are selective and non-selective inhibitors of MMPs. Batimastat, marimastat, GM-6001 (ilomastat or gelardin), PD-166793 and ONO4817 are non-selective inhibitors. However, semi-selective inhibitors (PY-2 and 1, and 2-HOPO-2) produce better results than non-selective inhibitors, since they are unstable due to proteolysis. PD-166793 and CGS270223A can improve re-perfusion ischemia [31]. CMT3 (chemically modified tetracycline-3) can inhibit MMP-2 and MMP-9 and therefore cardiac remodeling. Obviously more studies are required to identify more specific objective sites [87]. A promising idea for the treatment of cardiac fibrosis is based on the premise that cardiac fibroblasts can be reprogrammed into cardiomyocyte-like cells $[88,89]$. It is not yet known if this type of therapy can be used in human.

\section{Liver}

The process of hepatic fibrosis is dynamic. Since hepatocytes are capable of regeneration, liver fibrosis may be especially amenable to therapeutic intervention, and even cirrhosis can be reversed [90,91]. Eradication of HCV infection, antiviral therapy for HBV infection, glucocorticoid therapy for autoimmune hepatitis, phlebotomy for hemochromatosis, relief of biliary obstruction, and cessation of alcohol consumption in alcoholic hepatitis each clearly reverses fibrotic change, and many of these treatments improve clinical outcomes [92,93].

Despite recent enthusiasm with the use of antioxidants in fibrosis and experimental studies, solid clinical efficacy data in humans are very limited [46]. Inhibition of liver damage can be implemented in several ways; namely: fibropreventive, fibrostatic or fibrolytic drugs. Obeticolic acid (OCA, and INT-747), has anticolestastial and hepatoprotective properties, increases insulin sensitivity, modulates the metabolism of fats and has anti-inflammatory and antifibrotic properties. Both alternatives are under clinical evaluation and OCA significantly reduced fibrosis in clinical work in patients with NASH [94]. OCAs and similar drugs target FXR receptors. Best known are the endogenous agonists of these FXR receptors such as chenodeoxycholic acid, deoxycholoic acid, cholic acid and lithocholic acid. In general, these medications improve glucose metabolism, increase insulin sensitivity, reduce hepatic lipogenesis and increase $\beta$-oxidation.

Drugs that reduce the intestinal absorption of cholesterol, increase bile flow and change the hydrophobicity index of the pool of bile acids, cause anti-inflammatory effects. UDCA (steroid bile acid ursodeoxycholic acid) and nor UDCA (short chain homolog) increase the cholehepatic shunt, are also therapeutic options $[95,96]$. An alternative that requires future studies in humans is to neutralize osteopontin (increases TGF- $\beta$ and induces fibrogenesis) and the use of pentraxins which are proteins that bind directly to monocytes, neutrophils and macrophages, modifying their activation, dissemination and polarization and inhibiting their differentiation to fibrocytes [97,98].

Recent strategies are in development. For example, induce apoptosis, senescence or deactivation of the cells that produce ECM [99]. Sequestering profibrotic cytokines could be effective. For example, sequestering TGF- $\beta$ and its receptors, or PDGF and its signals with multikinases and aptamers, was investigated experimentally and in preclinical studies [100]. An antibody against lysyl-oxidase-like 2 (LOXL2), involved in collagen crosslinking; simtuzumab, has not shown activity in patients with hepatic fibrosis [101]. Microbiotic is 
the sum and composition of the microorganisms of the gastrointestinal tract. It is conceivable that manipulating it with antifibrotic microbes could, in the future, be established as a treatment in human liver disease $[102,103]$.

Viral eradication (antiviral drugs), removal of parasites (praziquantel for Schistosma), and suspension of toxins or drugs can restore liver architecture. It should be remembered that this fibrotic process is dynamic and even advanced fibrosis can be recovered [104]. Portal thrombosis and venous obstruction are frequent in liver cirrhosis and advanced fibrosis. Use of low molecular weight heparin (enoxaparin) can prevent portal vein thrombosis, hepatic decompensation, and reduce mortality in patients with advanced liver cirrhosis [105].

NAFLD (non-alcoholic fatty liver disease) (afflict 30\% of the general population in the Western world), NASH (non-alcoholic steatohepatitis), diabetes mellitus, and metabolic syndrome could be prevented with a healthy diet, weight loss and regular physical activity, but the hectic and stressful nature of modern life, and the industry's propaganda of foods rich in sugars and fats impede such adjustments. Several pharmacological attempts are under scrutiny. In 516 patients with biopsy-proven $\mathrm{NASH}$, the use of thiazolidinedione (rosiglitazone or pioglitazone) was associated with improvement in NASH resolution and fibrosis, even in patients without diabetes [106]. Other candidate drugs are: the glucagon-like peptide- 1 receptor (GCP-1R), and the FXR agonist as OCA (INT-747) that is currently in phase 2 and 3 studies in various types of fibrosing liver disease. Vitamin $\mathrm{E}$ has beneficial effects on liver enzymes, steatosis, inflammation, hepatocyte ballooning and hepatic fibrosis [107]. Selonsertib (CS-4997), an inhibitor of apoptosis signal-regulating kinase (ASK1) has been shown to reduce fibrosis in patients with NASH and fibrosis in stages 2-3 [108]. Other drugs such as cenicriviroc and elafibronor are still under investigation [109-111].

\section{Kidney}

Like the therapies used to treat cardiac fibrosis, those typically used to prevent renal fibrosis target the underlying disease processes and as such involve the treatment of hypertension and diabetes. One target is the renin-angiotensin system. This approach involves the use of ACE inhibitors and angiotensin-receptor blockers that ameliorate renal damage and fibrosis through multiple pathways, including the suppression of the actions of TGF- $\beta$ [112]. Therapies based on the antagonism of aldosterone that make use of mineralocorticoid receptor antagonists have been shown to inhibit or slow the progression of fibrosis in humans [113]. Novel approaches to the treatment of fibrosis of the kidneys include those that target bone morphogenetic protein-7, NADPH oxidase (NOX) (NOX1 and NOX4), and the SMAD3 and SMAD4 pathways [114].

\section{Lung}

The lung presents special challenges with regard to therapy targeting fibrosis. On the one hand, the lung has easily measured clinical features that allow for assessment of lung function, a surrogate for fibrosis. On the other hand, pulmonary fibrosis appears to be less dynamic than fibrosis occurring in other organ systems. Non-pharmacologic management strategies help patients with IPF live healthier, more normal lives, and the importance of these approaches cannot be overemphasized. Smoking cessation should be a priority for patients who are actively using tobacco products. Influenza, pneumococcal, and other age-appropriate vaccines should be administered [85]. Clinical practice guidelines strongly recommend supplemental oxygen for patients with IPF [63]. Oxygen administration reduces exertional dyspnea and improves exercise tolerance [115]. An oxyhemoglobin saturation of $88 \%$ or less at rest, during exertion, or during sleep should prompt initiation of home oxygen therapy [116]. Pulmonary rehabilitation, a structured exercise program designed for adults with advanced lung disease, has been shown to improve exercise capacity and health-related quality of life for patients with IPF [117]

Only a minority of patients with IPF receive a transplant [118]. Lung transplantation can prolong survival and improve quality of life for highly selected candidates $[119,120]$; however, only $66 \%$ of transplant recipients with IPF survive for more than 3 years after transplantation and only 53\% survive for more than 5 years [118]. Common complications include primary graft dysfunction, acute and chronic forms of allograft rejection, cytomegaloviral and other infections, and cancer [118]. IPF has not been shown to recur in the allograft. Referral to a transplantation center should be made at the time of diagnosis, since the evaluation process and waiting time can last for months to years [121]. Common contraindications include recent cancer, advanced non-pulmonary organ failure, and lack of a reliable social support system [122]. Poverty, meager health budgets and little experience of health personnel with this tool threaten the possibility of implementing them successfully in third world countries,

Treatment guidelines for IPF include a strong recommendation against the use of prednisone in combination with azathioprine and oral $\mathrm{N}$-acetylcysteine, a regimen associated with an increase in mortality by a factor of 9 , as compared with placebo. Interferon- $\gamma$, [123], endothelin antagonists, [124] and warfarin [125] are ineffective or harmful in patients with IPF. The Food and Drug Administration has appropriately warned consumers against various unapproved stem-cell "therapies" advertised for the treatment of IPF [126]. Although current guidelines recommend the use of antacid therapy to treat IPF, there are no data from clinical trials to support this recommendation [63]. More recent data suggest that antacid therapy may increase the risk of respiratory infections in patients with IPF [127].

Two medications, nintedanib and pirfenidone, have been shown to be safe and effective in the treatment of IPF; both are recommended for use in patients with IPF [63]. In placebo-controlled, randomized trials, each drug has been shown to slow the rate of FVC decline by approximately $50 \%$ over the course of 1 year $[128,129]$. Both have shown some efficacy in reducing severe respiratory events, such as acute exacerbations, and hospitalization for respiratory events $[130,131]$. Pooled data and meta-analyses suggest that these agents may reduce mortality $[132,133]$. The cost of each medication is estimated to exceed $\$ 100,000$ annually. Again, in low-income countries it is very difficult to implement these therapies on a regular basis for patients with IPF due to its high cost, especially that they are of indefinite use.

Nintedanib is a tyrosine kinase inhibitor that targets growth factor pathways, including those downstream from VEGF receptors 1, 2, and 3, CGF receptors 1, 2, and 3, and PDGF receptor. Patients should initially be prescribed $150 \mathrm{mg}$ of nintedanib, to be taken by mouth twice daily. The dose can be decreased to $100 \mathrm{mg}$ twice daily if unmanageable side effects occur. The medication should be taken with food and can be continued indefinitely. Patients taking nintedanib commonly have diarrhea, which can often be managed with antidiarrheal agents [128]. Cases of drug-induced liver injury have been reported. Liver function should be tested at baseline, monitored monthly for the first 3 months, and then monitored as clinically indicated. Since nintedanib is associated with a small increase in the risk of bleeding, this agent 
should be used with great caution, if at all, in patients receiving full-dose anticoagulant therapy. Atheroembolic events, including myocardial infarction, have also been reported with nintedanib [128]. Caution should be used when treating patients with cardiovascular risk factors, including those who have coronary artery disease.

Pirfenidone has a number of anti-inflammatory and anti-fibrotic effects, including inhibition of collagen synthesis, down-regulation of TGF- $\beta$ and TNF- $\alpha$, and a reduction in fibroblast proliferation [134]. Pirfenidone is prescribed in an escalating-dose fashion over a 14-day period: $267 \mathrm{mg}$ (one capsule) by mouth three times daily for 1 week, $534 \mathrm{mg}$ (two capsules) three times daily for 1 week, and $801 \mathrm{mg}$ (three capsules) three times daily thereafter. Patients can subsequently be transitioned to an 801-mg tablet three times daily. Pirfenidone must be taken with food and can be continued indefinitely. Common side effects, such as anorexia, nausea, and vomiting, [129] can often be ameliorated by judicious use of antacids and antiemetic agents. In some cases, side effects are severe enough to require a lower total daily dose (six to eight capsules daily). A photosensitive rash can also occur. Liver function should be monitored periodically.

Pirfenidone and nintedanib provide similar benefits $[135,136]$. Recent data on treatment that combines these agents suggest clinically significant gastrointestinal side effects [137]. It is difficult to recommend one agent over the other, since there have been no headto-head comparisons.

There are several possible approaches for the management of cough in IPF, though none are universally effective. Thalidomide be used to ameliorate cough in patients with IPF [138]. An observational study suggests that pirfenidone may attenuate cough [139]. The P2X3 antagonist AF-219/MK-7264 (gefapixant) suppresses idiopathic cough [140]; a trial of this agent in patients with IPF has been completed (NCT02502097). Finally, an inhaled cromolyn preparation was shown to ameliorate cough in patients with IPF [141].

\section{Future directions}

Fibrosis is a hallmark of pathologic remodeling in numerous tissues and a contributor to clinical disease. Thus, it is important to understand the central mechanisms underlying the fibrogenic process. A major conserved cellular element is the activated fibroblast, also known as a myofibroblast, which produces abundant amounts of ECM. Some of the major conserved molecular processes involve TGF- $\beta$, PDGF, CTGF, vasoactive compounds (endothelin-1 and angiotensin II), and integrin-extracellular matrix signaling pathways. The fact that tissue fibrosis is remarkably plastic suggests that many of these major elements of disease pathogenesis may emerge as targets of novel therapeutic interventions. Novel preventive interventions, evolving use of screening biomarkers, and the eventual ability to target newly discovered risk factors for fibrosis could lead to a decline in the incidence of associated diseases in coming years. Advances in therapeutics, including individualized approaches and interventions to halt collagen deposition, may turn the associated pathologies into lifelong chronic diseases.

\section{Source of economic support}

No.

\section{Conflict of interest}

No.

\section{Author contribution}

This work was only carried out by the author. Author AA contributed in the planning, data collection, data analysis, writing and critical review. AA read and approved the final manuscript.

\section{References}

1. Rennard SI (2004) Antiinflammatory therapies other than corticosteroids. Proc Am Thorac Soc 1: 282-287. [Crossref]

2. Rockey DC, Bell PD, Hill JA (2015) Fibrosis--a common pathway to organ injury and failure. N Engl J Med 372: 1138-1149. [Crossref]

3. Wynn TA (2004) Fibrotic disease and the $\mathrm{T}(\mathrm{H}) 1 / \mathrm{T}(\mathrm{H}) 2$ paradigm. Nat Rev Immunol 4: 583-594. [Crossref]

4. MassaguÃ@ J1 (2012) TGFî ${ }^{2}$ signalling in context. Nat Rev Mol Cell Biol 13: 616-630 [Crossref]

5. Guo X, Wang XF (2009) Signaling cross-talk between TGF-beta/BMP and other pathways. Cell Res 19: 71-88. [Crossref]

6. Cigna N, Farrokhi Moshai E, Brayer S, Marchai-Somme J, Wémearu-Stervinou L. et al. (2012). The hedgehog system machinery control transforming growth factorB-dependent myofibroblastic differentiation in humans: involvement in idiopathic pulmonary fibrosis. Am J Pathol 181: 2126-2137.

7. Wynn TA (2007) Common and unique mechanisms regulate fibrosis in various fibroproliferative diseases. J Clin Invest 117: 524-529. [Crossref]

8. Khimji AK, Rockey DC (2010) Endothelin--biology and disease. Cell Signal 22: 16151625. [Crossref]

9. Johnson A, DiPietro LA (2013) Apoptosis and angiogenesis: an evolving mechanism for fibrosis. FASEB J 27: 3893-3901. [Crossref]

10. Shechter R, Raposo C, London A, Sagi I, Schwartz M (2011) The glial scar-monocyte interplay: a pivotal resolution phase in spinal cord repair. PLoS One 6: e27969. [Crossref]

11. Du X, Shimizu A, Mazuda Y, Kuwahara N, Arai T, et al. (2012). Involvement of metalloproteinase- 2 in the development of renal interstitial fibrosis in mouse obstructive nephropathy. Lab Invest 97: 1149-1160.

12. Zhou W, Otto EA, Cluckey A, Airik R, Hurd TW, et al (2012). FAN1 mutations cause karyomegalic interstitial nephritis, linking chronic failure to defective DNA damage repair. Nat Genet 44: 910-915

13. Tian C, Stokowski RP, Kershenobich D, Ballinger DG, Hinds DA (2010) Variant in PNPLA3 is associated with alcoholic liver disease. Nat Genet 42: 21-23. [Crossref]

14. Romeo S, Kozlitina J, Xing C, Pertsemlidis A, Cox A, et al (2008). Genetic variations in PNPLA3 confer susceptibility to nonalcoholic fatty liver disease. Nat Genet 40 : 1461-1465.

15. Huang H, Shiffman ML, Friedman S, Venkatesh R, Bzowei N, et al. (2007). A 7 gene signature identifies the risk of developing cirrhosis in patients with chronic hepatitis $\mathrm{C}$. Hepatology 14: 297-306.

16. Tefferi A, Guglielmelli P, Pardanani A, Vannucchi AM (2018) Myelofibrosis Treatmen Algorithm 2018. Blood Cancer J 8: 72. [Crossref]

17. Chan RH, Maron BJ, Olivotto I, Pencina MJ, Assenza GE, et al. (2014). Prognostic value of quantitative contrast-enhanced cardiovascular magnetic resonance for the evaluation of sudden death risk in patients with hypertrophic cardiomyopathy: a metaanalysis. Heart 101: 1406-1411.

18. Alder JK, Chen JJ, Lancaster L, Danoff S, Su SC, et al. (2008) Short telomeres are a risk factor for idiopathic pulmonary fibrosis. Proc Natl Acad Sci U S A 105: 1305113056. [Crossref]

19. Armanios MY, Chen JJ, Cogan JD, Alder JK, Ingersoll RG, et al. (2007) Telomerase mutations in families with idiopathic pulmonary fibrosis. $N$ Engl J Med 356: $1317-$ 1326. [Crossref]

20. Fingerlin TE, Murphy E, Zhang W, Pelito L, Brown KK, et al (2013). Genome-wide association study identifies multiple susceptibility loci for pulmonary fibrosis. Nat Genet 45: 613-620.

21. Allen RJ, Porter J, Braybrooke R, Flores C, Fingerlin TE, et al. (2017) Genetic variants associated with susceptibility to idiopathic pulmonary fibrosis in people of Europe ancestry: a genome-wide association study. Lancet Respir Med 5: 869-880. 
22. Seibold MA, Wise AL, Speer MC, Steele MP, Brown KK, et al. (2011) A common MUC5B promoter polymorphism and pulmonary fibrosis. $N$ Engl J Med 364: 15031512. [Crossref]

23. Roy MG, Livraghi-Butrico A, Fletcher AA, McElwee MM, Evans SE, et al. (2014) Muc $5 \mathrm{~b}$ is required for airway defence. Nature 505: 412-416. [Crossref]

24. Nakano Y, Yang IV, Walts AD, Watson AM, Helling BA, et al. (2016). MUC5B promoter variant rs35705950 affects MUC5B expression in the distal airways in idiopathic pulmonary fibrosis. Am J Respir Crit Care Med 193: 464-466.

25. Molyneaux PL, Willis-Owen SAG, Cox MJ, James P, et al. (2017) Host-Microbial Interactions in Idiopathic Pulmonary Fibrosis. Am J Respir Crit Care Med 195: 16401650. [Crossref]

26. Morris A, Gibson K, Collman RG (2014) The lung microbiome in idiopathic pulmonary fibrosis. What does it mean and what should we do about it? Am J Respir Crit Care Med 190: 850-852. [Crossref]

27. Putta S, Lanting L, Sun G, Lawson G, Kato M, et al. (2012) Inhibiting microRNA-192 ameliorates renal fibrosis in diabetic nephropathy. J Am Soc Nephrol 23: 458-469. [Crossref]

28. Lakner AM, Steuerwald NM, Walling TM, Ghosh S, Li T, et al. (2012). Inhibitory effects of microRNA19b in hepatic stellate cell-mediated fibrogenesis. Hepatology 56: 300-310.

29. van Rooij E, Olson EN (2009) Searching for miR-acles in cardiac fibrosis. Circ Res 104: 138-140. [Crossref]

30. Huang SK, Scruggs AM, McEachin RC, White ES, Peters-Golden M (2014) Lung fibroblasts from patients with idiopathic pulmonary fibrosis exhibit genome-wide differences in DNA methylation compared to fibroblasts from non-fibrotic lung. PLoS One 9: e107055-e107055

31. Liu T, Song D, Dong J, Zhu P. Liu W, et al. (2017) Current understanding of the pathophysiology of myocardial fibrosis and its quantitative assessment in heart failure. Front Physiol 24: 238

32. Ruparelia N, Chai JT, Fisher EA, Choudhuhy RP. (2017). Inflammatory process in cardiovascular disease: a route to targeted therapies. Nat Rev Cardiol 14: 133-144.

33. Burchfield JS, Xie M, Hill JA (2013) Pathological ventricular remodeling: mechanisms: part 1 of 2. Circulation 128: $388-400$

34. Falkenham A, de Antueno RT, Rosin N, Betsch D, Lee TD, et al (2015). Non-classical resident macrophages are important determinants in the development of myocardial fibrosis. Am J Pathol 185: 927-942.

35. Heymans S, González A, Pizard A, Papageorgiou AP, et al. (2015) Searching for new mechanisms of myocardial fibrosis with diagnostic and/or therapeutic potential. Eur $J$ Heart Fail 17: 764-771. [Crossref]

36. Kong P, Christia P, Frangogiannis NG (2014) The pathogenesis of cardiac fibrosis. Cell Mol Life Sci 71: 549-574. [Crossref]

37. Segura AM, Frazier OH, Buja LM (2014) Fibrosis and heart failure. Heart Fail Rev 19: 173-185. [Crossref]

38. Spinale FG (2007) Myocardial matrix remodeling and the matrix metalloproteinases: influence on cardiac form and function. Physiol Rev 87: 1285-1342.

39. Martin ML, Blaxall BC (2012) Cardiac intercellular communication: are myocytes and fibroblasts fair-weather friends? J Cardiovasc Transl Res 5: 768-782.

40. Tanaka K, Zlochiver S, Vikstrom KL, Yamazaki M, Moreno J, et al. (2007) Spatia distribution of fibrosis governs fibrillation wave dynamics in the posterior left atrium during heart failure. Circ Res 101:839-847.

41. Miragoli M, Salvarani N, Rohr S (2007) Myofibroblasts induce ectopic activity in cardiac tissue. Circ Res 101: 755-758. [Crossref]

42. Ahmad T, Fiuzat M, Neely B, Neely ML, Pencina MJ, et al. (2014) Biomarkers of myocardial stress and fibrosis as predictors of mode of death in patients with chronic heart failure. JACC Heart Fail 2: 260-268. [Crossref]

43. Lagan J, Schmitt M, Miller CA (2017) Clinical applications of multi-parametric CMR in myocarditis and systemic inflammatory diseases. Int $J$ Cardiovasc Imaging 34: 35-54.

44. Liu T, Ma T, Liu W, Ling S, Zhao C (2016) Late gadolinium enhancement amount as an independent risk factor for the cardiovascular events in patients with stage $\mathrm{C}$ or D heart failure. Front Physiol 7: 484.

45. Barrison A, Del Toro A, Chiapping S, Aguaro CD, Todiere G, et al. (2015) Prognostic significance of myocardial extracellular volume fraction in non ischaemic dilated cardiomyopathy. J Cardiovasc Med 16: 681-686.
46. Weiskirchen R, Weiskirchen S, Tecke F (2018) Recent advances in understanding liver fibrosis: bridging basis science and individualized treatment concepts (version 1 , referees: 2 approved). F100Research p. 1-14.

47. Seki E, De Minicis S, Osterreicher CH, Kluwe J, Osawa Y, et al. (2007) TLR4 enhances TGF-beta signaling and hepatic fibrosis. Nat Med 13: 1324-1332. [Crossref]

48. Fouts DE, Torralba M, Nelson KE, Brenner DA, Schnabl B (2012) Bacteria translocation and changes in the intestinal microbiome in mouse models of liver disease. J Hepatol 56: 1283-1292.

49. Weiskirchen R, Tacke F (2016) Liver Fibrosis: From Pathogenesis to Novel Therapies Dig Dis 34: 410-422. [Crossref]

50. Weiskirchen R, Weiskirchen S, Tacke F (2018) Organ and tissue fibrosis: molecula signals, cellular mechanisms and translational implications. Mol Aspects Med S00982997: 30038-30044

51. Cruz-Ramón V, Chinchilla-López P, Ramírez-Pérez O, Méndez-Sánchez N (2017) Bile Acids in Nonalcoholic Fatty Liver Disease: New Concepts and therapeutic advances. Ann Hepatol 16: s58-s67.

52. Ramírez-Pérez O1, Cruz-Ramón V1, Chinchilla-López P1, Méndez-Sánchez N1 (2017) The Role of the Gut Microbiota in Bile Acid Metabolism. Ann Hepatol 16(Suppl) [Crossref]

53. Sanyal AJ, Bosch J, Blei A, Arroyo V (2008) Portal hypertension and its complications. Gastroenterology 134: 1715-1728.

54. Sutariya B, Jhonsa D, Saraf MN (2016) TGF- $\hat{I}^{2}$ : the connecting link between nephropathy and fibrosis. Immunopharmacol Immunotoxicol 38: 39-49. [Crossref]

55. Mezzano SA, Ruiz-Ortega M, Egido J (2001) Angiotensin II and renal fibrosis. Hypertension 38: 635-638. [Crossref]

56. Kang HM, Ahn SH, Choi P, Ko YA, Han SH, et al. (2015) Defective fatty acid oxidation in renal tubular epithelial cells has a key role in kidney fibrosis development Nat Med 21: 37-46.

57. Zhou D, Li Y, Zhou L, Tan RJ, Xiao L, et al. (2014) Sonic hedgehog is a novel tubulederived growth factor for interstitial fibroblasts after kidney injury. J Am Soc Nephrol 25: $2187-2200$.

58. Kramann R, Fleig SV, Schneider RK, Fabian SI, DiRocco DP, et al. (2015) Pharmacological GLI2 inhibition prevents myofibroblast cell-cycle progression and reduces kidney fibrosis. J Clin Invest 125: 2935-2951.

59. Sun Y, Liu Y, Li Ch. Wang X, Zho R, et al. (2017) Recent advances of curcumin in the prevention and treatment of renal fibrosis. BioMed Res Int p. 1-9.

60. Zhou D, Liu Y (2016) Renal fibrosis in 2015: Understanding the mechanisms of kidney fibrosis. Nat Rev Nephrol 12: 68-70. [Crossref]

61. Liu Y (2011) Cellular and molecular mechanisms of renal fibrosis. Nat Rev Nephrol 7: 684-696. [Crossref]

62. Rosas IO, Dellaripa PF, Lederer DJ, Khanna D, Young LR, et al. (2014) Interstitial lung disease: NHLBI Workshop on the Primary Prevention of Chronic Lung Diseases. Ann Am Thorac Soc 11 Suppl 3: S169-177. [Crossref]

63. Raghu G, Collard HR, Egan JJ, Martinez FJ, Behr J, et al (2011). An official ATS ERS/JRS/ALAT statement: idiopathic pulmonary fibrosis: evidence-based guidelines for diagnosis and management. Am J Respir Crit Care Med 183: 788-824.

64. Esposito DB, Lanes S, Donneyong M, Holick CN, Lasky JA, et al (2015). Idiopathic pulmonary fibrosis in United States automated claims: incidence, prevalence, and algorithm validation. Am J Respir Crit Care Med 192: 1200-1207.

65. Raghu G, Chen SY, Hou Q, Yeh WS, Collard HR (2016) Incidence and prevalence of idiopathic pulmonary fibrosis in US adults 18-64 years old. Eur Respir J 48: 179-186. [Crossref]

66. Hewson T, McKeever TM, Gibson JE, Navaratnam V, Hubbard RB, et al. (2017) Timing of onset of symptoms in people with idiopathic pulmonary fibrosis. Thorax.

67. Selman M, Pardo A (2014) Revealing the pathogenic and aging-related mechanisms of the enigmatic idiopathic pulmonary fibrosis. an integral model. Am J Respir Crit Care Med 189: 1161-1172.

68. Alder JK, Chen JJ, Lancaster L, Danoff S, Su SC, et al. (2008) Short telomeres are risk factor for idiopathic pulmonary fibrosis. Proc Natl Acad Sci U S A 105: 1305113056. [Crossref]

69. Armanios MY, Chen JJ, Cogan JD, Alder JK, Ingersoll RG, et al. (2007) Telomerase mutations in families with idiopathic pulmonary fibrosis. $N$ Engl J Med 356: $1317-$ 1326. [Crossref] 
70. Han MK, Zhou Y, Murray S, Tayob N, Noth I, et al. (2014). Lung microbiome and disease progression in idiopathic pulmonary fibrosis: an analysis of the COMET study. Lancet Respir Med 2: 548-556.

71. Molyneaux PL, Cox MJ, Willis-Owen SA, Mallia P, Russell KE, et al. (2014) The role of bacteria in the pathogenesis and progression of idiopathic pulmonary fibrosis. Am J Respir Crit Care Med 190: 906-913. [Crossref]

72. Baumgartner KB, Samet JM, Coultas DB, Stidley CA, Hunt WC, et al. (2000) Occupational and environmental risk factors for idiopathic pulmonary fibrosis: a multicenter case-control study. Collaborating Centers. Am J Epidemiol 152: 307-315. [Crossref]

73. Tobin RW, Pope CE II, Pellegrini CA, Emond MJ, Sillery J, et al. (1998). Increased prevalence of gastroesophageal reflux in patients with idiopathic pulmonary fibrosis. Am J Respir Crit Care Med 158: 1804-1808.

74. Kim JS, Podolanczuk AJ, Borker P, Kawuf SM, Kaufman JD, et al. (2017) Obstructive sleep apnea and subclinical interstitial lung disease in the Multi-Ethnic Study of Atherosclerosis (MESA). Ann Am Thorac Soc 14: 1786-1795.

75. Sack C, Vedal S, Sheppard L (2017) Air pollution and subclinical interstitial lung disease: the Multi-Ethnic Study of Atherosclerosis (MESA) air-lung study. Eur Respir J 50. [Crossref]

76. Tang YW, Johnson JE, Browning PJ, Cruz-Gervis RA, Davis A, et al. (2003) Herpesvirus DNA is consistently detected in lungs of patients with idiopathic pulmonary fibrosis. J Clin Microbiol 41: 2633-2640. [Crossref]

77. Kauffman CA (2009) Histoplasmosis. Clin Chest Med 30: 217-225. [Crossref]

78. Rossi SE, McAdams HP, Rosado-de-Christenson ML, Franks TJ, Galvin JR (2001) Fibrosing mediastinitis. Radiographics 21: 737-757. [Crossref]

79. Tefferi A (2016) Primary myelofibrosis: 2017 update on diagnosis, risk-stratification, and management. Am J Hematol 91: 1262-1271. [Crossref]

80. Margadant C, Sonnenberg A (2010) Integrin-TGF-beta crosstalk in fibrosis, cancer and wound healing. EMBO Rep 11: 97-105. [Crossref]

81. Jinnin M (2010) Mechanisms of skin fibrosis in systemic sclerosis. J Dermatol 37: 11-25.

82. Swaminathan S, Horn TD, Pellowski D, Abul-Ezz S, Bornhorst JA, et al. (2007) Nephrogenic systemic fibrosis, gadolinium, and iron mobilization. N Engl J Med 357: 720-722. [Crossref]

83. Zeisberg M, Kalluri R (2013) Cellular mechanisms of tissue fibrosis: 1. common and organ-specific mechanisms associated with tissue fibrosis. Am J Physiol Cell Physiol 304: C216-C225.

84. Liaw YF (2013) Reversal of cirrhosis: an achievable goal of hepatitis B antiviral therapy. J Hepatol 59: 880-881. [Crossref]

85. Lederer DJ, Martinez FJ (2018) Idiopathic Pulmonary Fibrosis. N Engl J Med 378: 1811-1823. [Crossref]

86. Samuels CS, Bodaragama H, Chew JY, Widdop RE, Royce SG, et al. (2014). Serelaxin is a more efficacious antifibrotic than enalapril in an experimental model of heart disease. Hypertension 64: 315-322.

87. Mishra PK, Givvimani S, Chavali V, Tyagi SC (2013) Cardiac matrix: a clue for future therapy. Biochim Biophys Acta 1832: 2271-2276. [Crossref]

88. Song K, Nam YJ, Luo X, Qi X, Tan W, et al. (2012) Heart repair by reprogramming non-myocytes with cardiac transcription factors. Nature 485: 599-604. [Crossref]

89. Qian L, Huang Y, Spencer CI, Foley A, Vedantham V, et al. (2012). In vivo reprogramming of murine cardiac fibroblasts into induced cardiomyocytes. Nature 485: 593-598.

90. Liaw YF, Sung JJ, Chow WC, Farrell G, Lee CZ, et al. (2004) Lamivudine for patients with chronic hepatitis B and advanced liver disease. $N$ Engl J Med 351: 1521-1531. [Crossref]

91. Berenguer J, Alvarez-Pellicer J, Martín PM, Farrel G, Lee C-Z, et al. (2009) Sustained virological response to interferon plus ribavirin reduces liver-related complications and mortality in patients coinfected with human immunodeficiency virus and hepatitis $\mathrm{C}$ virus. Hepatology 50: 407-413.

92. Hammel P, Couvelard A, O'Toole D, Ratouis A, Sauvanet A, et al. (2001) Regression of liver fibrosis after biliary drainage in patients with chronic pancreatitis and stenosis of the common bile duct. $N$ Engl J Med 344: 418-423.

93. Maylin S, Martinot-Peignoux M, Moucari R, Boyer N, Ripault MP, et al. (2008). Eradication of hepatitis $\mathrm{C}$ virus in patients successfully treated for chronic hepatitis C. Gastroenterology 135: 821-829.
94. Neuschwander-Tetri BA, Loomba R, Sanyal AJ, Lavine JE, Van Natta ML, et al (2015). Farnesoid X nuclear receptor ligand obeticholic acid for non-cirrhotic, nonalcoholic steatohepatitis (FLINT): a multicentre, randomized, placebo-controlled trial. Lancet 385: 956-965.

95. Weiskirchen R (2016) Hepatoprotective and Anti-fibrotic Agents: It's Time to Take the Next Step. Front Pharmacol 6: 303. [Crossref]

96. Fickert P, Hirschfield GM, Denk G, Marschall HU, Altorjay I, et al. (2017) norUrsodeoxycholic acid improves cholestasis in primary sclerosing cholangitis. $J$ Hepatol 67: 549-558. [Crossref]

97. Kong X, Feng D, Wang H, Hong F, Bertola A, et al. (2012) Interleukin-22 induces hepatic stellate cell senescence and restricts liver fibrosis in mice. Hepatology 56: 1150-1159. [Crossref]

98. Bottazzi B, Inforzato A, Messa M, Barbagallo M, Magrini E, et al. (2016) The pentraxins PTX3 and SAP in innate immunity, regulation of inflammation and tissue remodelling. J Hepatol 64: 1416-1427. [Crossref]

99. Borkham-Kamphorst E, Schaffrath C, van de Leur E, Haas U, Thiaa L, et al. (2014) The anti-fibrotic effects of CCN1/CYR61 in primary portal myofibroblasts are mediated through induction of reactive oxygen species resulting in cellular senescence, apoptosis and attenuated TGF-ß signaling. Biochim Biophys Acta 1843: 902-914.

100. Borkham-Kamphorst E, Weiskirchen R (2016) The PDGF system and its antagonists in liver fibrosis. Cytokine Growth Factor Rev 28: 53-61. [Crossref]

101. Loomba R, Seguritan V, Li W, Long T, Klitgord N, et al. (2017). Gut MicrobiomeBased Metagenomic Signature for Non-invasive Detection of Advanced Fibrosis in Human Nonalcoholic Fatty Liver Disease. Cell Metab 25: 1054-1062.e5.

102. Ferrere G, Wrzosek L, Cailleux F, Turpin W, Puchois V, et al. (2017). Fecal microbiota manipulation prevents dysbiosis and alcohol-induced liver injury in mice. J Hepatol 66: 806-815.

103. García-Lezana T, Raurell I, Bravo M, Torres-Arauz M, Salcedo MT, et al. (2018) Restoration of a healthy intestinal microbiota normalizes portal hypertension in a rat model of nonalcoholic steatohepatitis. Hepatology 67: 1485-1498.

104. Pellicoro A, Ramachandran P, Iredale JP, Fallowfield JA. (2014). Liver fibrosis and repair: immune regulation of wound healing in a solid organ. Nat Rev Immunol 14: 181-194.

105. Villa E, Cammà C, Marietta M, Luogno M, Colopi S, et al. (2012). Enoxaparin prevents portal vein thrombosis and liver decompensation in patients with advanced cirrhosis. Gastroenterology 143: 1253-1260.e4.

106. Musso G, Cassader M, Paschetta E, Gambino R (2017) Thiazolidinediones and Advanced Liver Fibrosis in Nonalcoholic Steatohepatitis: A Meta-analysis. JAMA Intern Med 177: 633-640.

107. Sato K, Gosho M, Yamamoto T, Kobayashi Y, Ohashi T, et al. (2015). Vitamin E has a beneficial effect on nonalcoholic fatty liver disease: a meta-analysis of randomized controlled trials. Nutrition 31: 923-930.

108. Loomba R, Lawitz E, Mantry PS, Joyakumar S, Caldwell SH, et al. (2017). The ASK1 inhibitor selonsertib in patients with nonalcoholic steatohepatitis: A randomized, phase 2 trial. Hepatology.

109. Sumida Y, Yoneda M (2018) Current and future pharmacological therapies for NAFLD/NASH. $J$ Gastroenterol 53: 362-376. [Crossref]

110. Puengel T, Krenkel O, Kohlhepp M, Lefebvre E, Lueede T, et al. (2017). Differentia impact of the dual CCR2/CCR5 inhibitor cenicriviroc on migration of monocyte and lymphocyte subsets in acute liver injury. PLoS One 12: e0184694.

111. Krenkel O, Puengel T, Govaere O, Abdallah AT, Mossamen JC, et al. (2018) Therapeutic inhibition of inflammatory monocyte recruitment reduces steatohepatitis and liver fibrosis. Hepatology 67: 1270-1283.

112. Lambers Heerspink HJ, de Borst MH, Bakker SJ, Navis GJ (2013) Improving the efficacy of RAAS blockade in patients with chronic kidney disease. Nat Rev Nephrol 9: 112-121. [Crossref]

113. Bianchi S, Bigazzi R, Campese VM (2005) Antagonists of aldosterone and proteinuria in patients with CKD: an uncontrolled pilot study. Am J Kidney Dis 46: 45-51. [Crossref]

114. Tampe D, Zeisberg M (2014) Potential approaches to reverse or repair renal fibrosis Nat Rev Nephrol 10: 226-237. [Crossref]

115. Dowman LM, McDonald CF, Bozinovski S, Vlahos R, Gillies R, et al (2017). Greate endurance capacity and improved dyspnoea with acute oxygen supplementation in idiopathic pulmonary fibrosis patients without resting hypoxaemia. Respirology 22 957-964. 
116. Alvarado A (2017) Domiciliary oxygen: facts and fallacies. Clin Res Trials 3: 1-10.

117. Dowman LM, McDonald CF, Hill CJ, Lee A, Baker K, et al. (2017) The evidence of benefits of exercise training in interstitial lung disease: a randomized controlled trial. Thorax 72: 610-619.

118. Valapour M, Lehr CJ, Skeans MA, Smith JM, et al. (2018) OPTN/SRTR 2016 Annual Data Report: Lung. Am J Transplant 18 Suppl 1: 363-433. [Crossref]

119. Singer JP, Katz PP, Soong A, Shrestha P, Huang D, et al. (2017) Effect of lung transplantation on health-related quality of life in the era of the Lung Allocation Score: a U.S. prospective cohort study. Am J Transplant 17: 1334-1345.

120. Titman A, Rogers CA, Bonser RS, Banner NR, Sharples LD (2009). Disease-specific survival benefit of lung transplantation in adults: a national cohort study. $\mathrm{Am} \mathrm{J}$ Transplant 9: 1640-1649.

121. Weill D, Benden C, Corris PA, Deark JH, Davis RD, et al. (2015) A consensus document for the selection of lung transplant candidates: 2014 - an update from the Pulmonary Transplantation Council of the International Society for Heart and Lung Transplantation. J Heart Lung Transplant 34: 1-15.

122. The Idiopathic Pulmonary Fibrosis Clinical Research Network. (2012). Prednisone, azathioprine, and N-acetylcysteine for pulmonary fibrosis. N Engl J Med 366:19681977.

123. King TE Jr, Albera C, Bradford WZ, Costabel U, Hormel P, et al. (2009). Effect of interferon gamma-1b on survival in patients with idiopathic pulmonary fibrosis (INSPIRE): a multicentre, randomized, placebo-controlled trial. Lancet 374: 222 228 .

124. Raghu G, Behr J, Brown KK, Egan JJ, Kawut SM, et al. (2013) Treatment of idiopathic pulmonary fibrosis with ambrisentan: a parallel, randomized trial. Ann Intern Med 158: 641-649. [Crossref]

125. Noth I, Anstrom KJ, Calvert SB, de Andrade J, Flaherty KR, et al. (2012). A placebocontrolled randomized trial of warfarin in idiopathic pulmonary fibrosis. Am J Respir Crit Care Med 186: 88-95.

126. Marks PW, Witten CM, Califf RM (2017) Clarifying Stem-Cell Therapy's Benefits and Risks. $N$ Engl J Med 376: 1007-1009. [Crossref]

127. Kreuter M, Wuyts W, Renzoni E, Koschel D, Maher TM, et al. (2016). Antacid therapy and disease outcomes in idiopathic pulmonary fibrosis: a pooled analysis. Lancet Respir Med 4: 381-389.

128. Richeldi L, du Bois RM, Raghu G, Azuma A, Brown KK, et al. (2014) Efficacy and safety of nintedanib in idiopathic pulmonary fibrosis. N Engl J Med 370: 2071-2082. [Crossref]
129. King TE Jr, Bradford WZ, Castro-Bernardini S, Fagan EA, Glaspole I, et al. (2014) A phase 3 trial of pirfenidone in patients with idiopathic pulmonary fibrosis. $N$ Engl J Med 370: 2083-2092. [Crossref]

130. Ley B, Swigris J, Day BM, Stauffer JL, Raimundo K, et al. (2017). Pirfenidone reduces respiratory-related hospitalizations in idiopathic pulmonary fibrosis. $\mathrm{Am} \mathrm{J}$ Respir Crit Care Med 196: 756-761.

131. Costabel U, Inoue Y, Richeldi L, Collard HR, Tschoepe I, et al. (2016). Efficacy of nintedanib in idiopathic pulmonary fibrosis across pre-specified subgroups in INPULSIS. Am J Respir Crit Care Med 193: 178-185.

132. Nathan SD, Albera C, Bradford WZ, Costabel U, Glaspole I, et al. (2017). Effect of pirfenidone on mortality: pooled analyses and meta-analyses of clinical trials in idiopathic pulmonary fibrosis. Lancet Respir Med 5: 33-41.

133. Richeldi L, Cottin V, du Bois RM, Selman M, Kimura T, et al. (2016). Nintedanib in patients with idiopathic pulmonary fibrosis: combined evidence from the TOMORROW and INPULSIS trials. Respir Med 113: 74-79.

134. Kolb M, Bonella F, Wollin L (2017) Therapeutic targets in idiopathic pulmonary fibrosis. Respir Med 131: 49-57. [Crossref]

135. Vancheri C, Kreuter M, Richeldi L, Ryerson CJ, Valeyre D, et al. (2018). Nintedanib with add-on pirfenidone in idiopathic pulmonary fibrosis: results of the INJOURNEY Trial. Am J Respir Crit Care Med 197: 356-363.

136. Canestaro WJ, Forrester SH, Raghu G, Ho L, Devine BE (2016) Drug treatment of idiopathic pulmonary fibrosis: systematic review and network meta-analysis. Chest 149: $756-766$

137. Rochwerg B, Neupane B, Zhang Y (2016) Treatment of idiopathic pulmonary fibrosis: a network meta-analysis. BMC Med 14: 18. [Crossref]

138. Horton MR, Santopietro V, Mathew L, Horton KM, Polito AJ, et al. (2012) Thalidomide for the treatment of cough in idiopathic pulmonary fibrosis: a randomized trial. Ann Intern Med 157: 398-406.

139. van Manen MJG, Birring SS, Vancheri C, Vindigni V, Renzoni E, et al. (2017) Effect of pirfenidone on cough in patients with idiopathic pulmonary fibrosis. Eur Respir $J$ 50: $1701157-1701157$

140. Abdulqawi R, Dockry R, Holt K, Layton G, McCarthy BG, et al. (2015) P2X3 receptor antagonist (AF-219) in refractory chronic cough: a randomized, doubleblind, placebo-controlled phase 2 study. Lancet 385: 1198-1205.

141. Birring SS, Wijsenbeek MS, Agrawal S, van der Berg JWK, Stone H, et al. (2017) A novel formulation of inhaled sodium cromoglicate (PA101) in idiopathic pulmonary fibrosis and chronic cough: a randomized, double-blind, proof-of-concept, phase 2 trial. Lancet Respir Med 5: 806-815.

Copyright: (C2018 Alvarado A. This is an open-access article distributed under the terms of the Creative Commons Attribution License, which permits unrestricted use, distribution, and reproduction in any medium, provided the original author and source are credited. 